\title{
Listeria monocytogenes infection associated with methotrexate treatment for a patient with rheumatoid arthritis
}

\author{
MASAYA MUKAI ${ }^{1}$, TORU KAMEDA ${ }^{2}$, AKIHISA MATSUMOTO ${ }^{3}$, \\ ATSUSHI NOTOYA ${ }^{\prime}$ and MICHIFUMI KOHNO ${ }^{1}$ \\ ${ }^{\prime}$ Department of Clinical Immunology and Hematology, Sapporo City General Hospital, Kita 11-jo, \\ Nishi 13-chome, Kita-ku, Sapporo 060-8604, Japan \\ ${ }^{2}$ Department of Emergency Medicine, Sapporo City General Hospital, Kita 11-jo, Nishi 13-chome, \\ Kita-ku, Sapporo 060-8604, Japan \\ ${ }^{3}$ Department of Neurology, Sapporo City General Hospital, Kita 11-jo, Nishi 13-chome, Kita-ku, \\ Sapporo 060-8604, Japan
}

Received 6 February 1998; accepted 21 May 1998

\begin{abstract}
A 61-year-old women had been treated with methotrexate (MTX) since May 1993 for rheumatoid arthritis. She developed a high fever on 1 July 1997 and was diagnosed as having Listeria monocytogenes sepsis and meningoencephalitis. The encephalitis progressed inexorably and she died on $12 \mathrm{July.} \mathrm{Although} \mathrm{MTX} \mathrm{is} \mathrm{used} \mathrm{as} \mathrm{a} \mathrm{first-line} \mathrm{disease} \mathrm{modifying} \mathrm{anti-rheumatic} \mathrm{drug,} \mathrm{listeriosis}$ should be remembered as a potentially fatal adverse effect.
\end{abstract}

Key words: Methotrexate; Listeria monocytogenes infection; rheumatoid arthritis.

\section{INTRODUCTION}

Methotrexate (MTX) is one of the most effective disease modifying anti-rheumatic drugs (DMARDs). Although it has been recently used as a first-line drug for active rheumatoid arthritis (RA) in the US and Europe [1], there are many reports of adverse effects such as hepatic fibrosis, interstitial pneumonia and myelosuppression [2]. While these potential problems all require attention, infection has rarely been reported during MTX treatment for RA [3]. However, we encountered Listeria monocytogenes sepsis and meningoencephalitis associated with MTX treatment for RA. Although this is only the fourth case of listeriosis during MTX treatment for RA [3-5], the relationship seems to be important because the immune response to Listeria is reported to be inhibited by MTX [6]. Because MTX is expected to be increasingly used as a first- or a second-line DMARD [1], listeriosis should be remembered as a potentially fatal adverse effect. 


\section{CASE REPORT}

A 61-year-old Japanese woman had been suffering from polyarthritis and had been diagnosed as having RA at the Second Department of Medicine, Hokkaido University Hospital in March 1992. She had been initially treated with bucillamine (200 mg/day) without any effects since June 1992. Then her medication was changed to MTX (5 mg/week) in May 1993. As destructive joint involvement was progressing, the MTX dose was increased to $7.5 \mathrm{mg} /$ week in April 1994. Total right knee replacement was done in September 1995. After treatment with omeprazol for 6 weeks to control a duodenal ulcer from November 1995, famotidine was used for gastro-duodenal lesions. In June 1997, her medications were MTX (7.5 mg/week), loxoprofen (180 mg/day), famotidine (10 mg/day), rebamipide (300 mg/day), alfacalcidol ( $1 \mu \mathrm{g} /$ day $)$ and magnesium oxide $(0.6 \mathrm{~g} /$ day $)$, and her RA was inactive on these medications. Laboratory tests done in April 1997 revealed C-reactive protein (CRP) at $0.49 \mathrm{mg} / \mathrm{dl}$, white blood cells (WBC) at $3600 / \mathrm{mm}^{3}$, red blood cells $(\mathrm{RBC})$ at $3.61 \times 10^{6} / \mathrm{mm}^{3}$, hemoglobin $(\mathrm{Hb})$ at $11.5 \mathrm{~g} / \mathrm{dl}$, platelet (Plt) at $12.4 \times 10^{4} / \mathrm{mm}^{3}$, total protein (TP) at $6.9 \mathrm{~g} / \mathrm{dl}, \gamma$-globulin at $19.7 \%$, L-asparate 2-oxoglutarate transferase (AST) at $39 \mathrm{IU} / \mathrm{ml}$, L-alanine 2-oxoglutarate aminotransferase (ALT) at $27 \mathrm{IU} / \mathrm{ml}$, alkaline phosphatase (ALP) at $320 \mathrm{IU} / \mathrm{ml}$, blood urea nitrogen $(\mathrm{BUN})$ at $20 \mathrm{mg} / \mathrm{dl}$ and creatinine $(\mathrm{Cr})$ at $0.9 \mathrm{mg} / \mathrm{dl}$. Electrolytes showed no abnormalities.

She began to suffer from malaise in late June. As high fever occurred on 1 July, she went to the emergency clinic of Hokkaido University Hospital. An inflammatory reaction (CRP was $6.74 \mathrm{mg} / \mathrm{dl}$ ), liver dysfunction (AST was $72 \mathrm{IU} / \mathrm{ml}$, ALT was $71 \mathrm{IU} / \mathrm{ml}$ and lactate dehydrogenase $(\mathrm{LDH})$ was $758 \mathrm{IU} / \mathrm{ml}$ ), leucopenia (WBC was $2900 / \mathrm{mm}^{3}$ ) and thrombocytopenia (Plt was $10 \times 10^{4} / \mathrm{mm}^{3}$ ) were detected. Her chest X-ray film and abdominal ultrasonic examination were normal. When she went to the Second Department of Medicine, Hokkaido University Hospital on 2 July because of continuous high fever, she was hospitalized, then she was referred to our hospital and was transferred in the evening. Her consciousness was slightly clouded (level 1 on the Japan coma scale), but physical examination showed no specific abnormalities. There was no Kernig's sign or neck rigidity. Laboratory tests done on admission revealed CRP at $12.4 \mathrm{mg} / \mathrm{dl}$, total bilirubin (TB) at $1.5 \mathrm{mg} / \mathrm{dl}$, $\mathrm{ALP}$ at $380 \mathrm{IU} / \mathrm{ml}$, AST at $50 \mathrm{IU} / \mathrm{ml}, \mathrm{ALT}$ at $66 \mathrm{IU} / \mathrm{ml}, \mathrm{LDH}$ at $901 \mathrm{IU} / \mathrm{ml}$, TP at $6.8 \mathrm{~g} / \mathrm{dl}, \mathrm{Na}^{+}$at $128 \mathrm{mEq} / 1, \mathrm{~K}^{+}$at $4.2 \mathrm{mEq} / 1, \mathrm{Cl}^{-}$at $91 \mathrm{mEq} / 1, \mathrm{BUN}$ at $14 \mathrm{mg} / \mathrm{dl}$, $\mathrm{Cr}$ at $0.7 \mathrm{mg} / \mathrm{dl}, \mathrm{WBC}$ at $4000 / \mathrm{mm}^{3}$ (granulocytes $72 \%$, lymphocytes $11 \%$ and monocytes $7 \%$ ), RBC at $3.24 \times 10^{6} / \mathrm{mm}^{3}, \mathrm{Hb}$ at $10.1 \mathrm{~g} / \mathrm{dl}$, Plt at $8.9 \times 10^{4} / \mathrm{mm}^{3}$, prothrombin time (PT) at $81 \%$, active partial prothrombin time (aPTT) at $30 \mathrm{~s}$ and fibrinogen at $351 \mathrm{mg} / \mathrm{dl}$. Anti-nuclear antibody and rheumatoid factor were negative. She was diagnosed as having infection and so was treated with $4 \mathrm{~g} /$ day of cefmetazole sodium (CMZ). However, her high fever persisted on the next day. As Gram-positive rods were detected in venous specimens, she was diagnosed as having sepsis of unknown origin and $\gamma$-globulin was added to her treatment. On 4 July, her level of consciousness was much worse (20 on the Japan coma scale), 

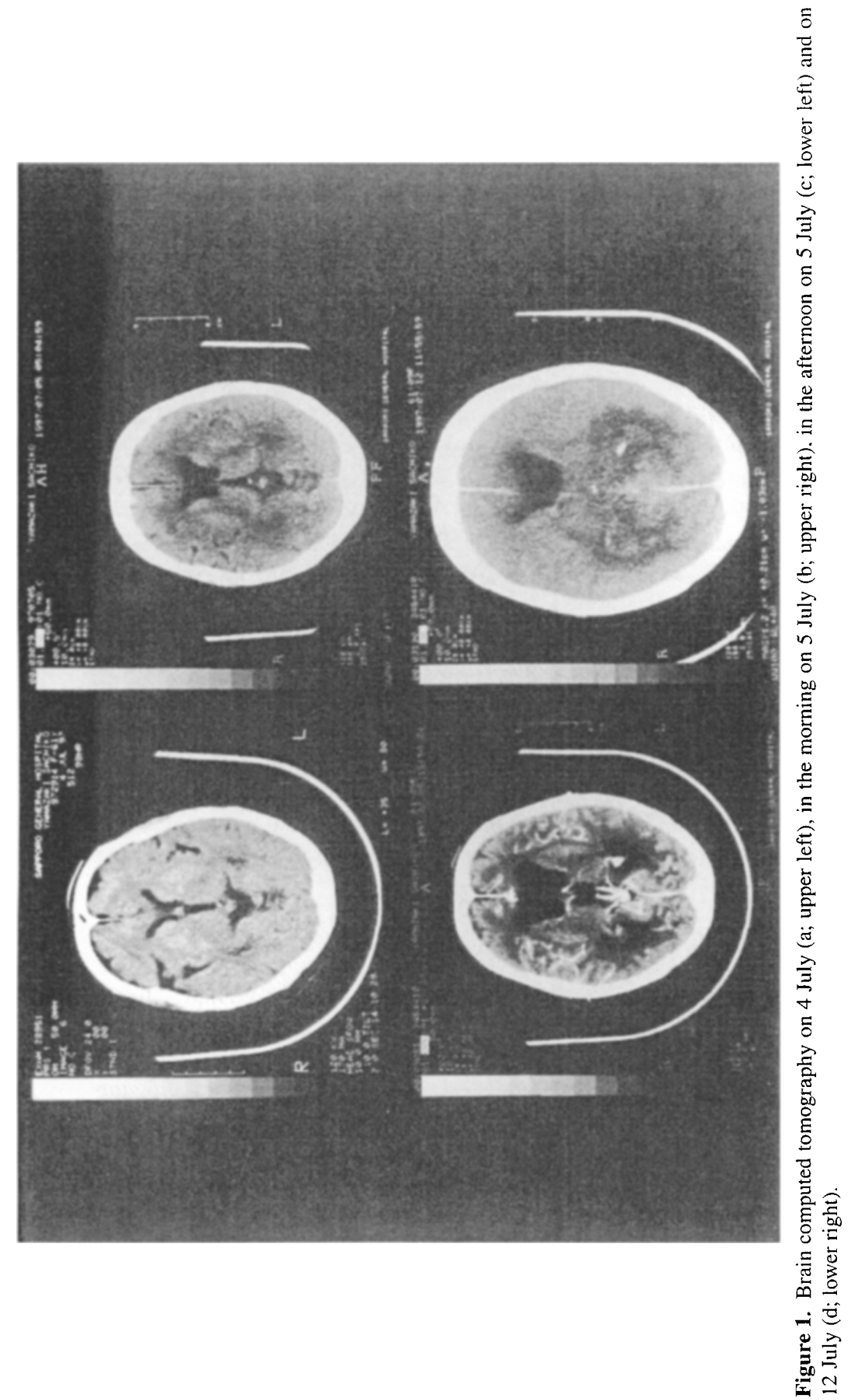
so lumbar puncture was done. Although the opening pressure was $180 \mathrm{mmH}_{2} \mathrm{O}$, her liquor revealed cells elevated to $622 / 3 / \mathrm{mm}^{3}$ (mononuclear cells were $167 / 3$ and polymorphonuclear cells were $455 / 3$ ), protein elevated to $406 \mathrm{mg} / \mathrm{dl}$ and glucose decreased to $4 \mathrm{mg} / \mathrm{dl}$. Immunoglobulin $\mathrm{G}$ concentrations were $1250 \mathrm{mg} / \mathrm{dl}$ in serum and $72.5 \mathrm{mg} / \mathrm{dl}$ in liquor. Tests revealed a CRP at $14.29 \mathrm{mg} / \mathrm{dl}$, ALP at $274 \mathrm{IU} / \mathrm{ml}$, AST at $35 \mathrm{IU} / \mathrm{ml}, \mathrm{ALT}$ at $42 \mathrm{IU} / \mathrm{ml}, \mathrm{LDH}$ at $807 \mathrm{IU} / \mathrm{ml}, \mathrm{TP}$ at $5.7 \mathrm{~g} / \mathrm{dl}$, $\mathrm{Na}^{+}$at $125 \mathrm{mEq} / \mathrm{l}, \mathrm{K}^{+}$at $3.7 \mathrm{mEq} / 1, \mathrm{Cl}^{-}$at $91 \mathrm{mEq} / 1, \mathrm{BUN}$ at $9 \mathrm{mg} / \mathrm{dl}, \mathrm{Cr}$ at $0.7 \mathrm{mg} / \mathrm{dl}$, WBC at $12100 / \mathrm{mm}^{3}$ (granulocytes $87 \%$, lymphocytes $10 \%$ and monocytes $3 \%$ ), RBC at $2.61 \times 10^{6} / \mathrm{mm}^{3}, \mathrm{Hb}$ at $8.5 \mathrm{~g} / \mathrm{dl}$ and Plt at $3.6 \times 10^{4} / \mathrm{mm}^{3}$. She was diagnosed as having meningoencephalitis and disseminated intravascular coagulation (DIC). Her treatment was changed from CMZ to cefotaxime sodium (CTX) (4 g/day) and gabexate mesilate was added. Computed tomography (CT) of the brain (Fig. 1a) showed no definite abnormalities and no cerebral edema.

Her level of consciousness and her respiratory status worsened at night. Because respiratory arrest occurred at 2 a.m. on 5 July, she was transferred to the intensive care unit and was placed on a ventilator. Whole body CT scans showed no abscess and only detected an uterine myoma. Because mild cerebral edema was shown on the brain CT scan obtained at 5 a.m. (Fig. 1b) and the rod bacteria in her blood culture were determined to be L. monocytogenes, the antibiotic was changed to piperacillin sodium (PIPC) and glycerin was therapy added for intracranial hypertension. The isolated L. monocytogenes was sensitive to many antibiotics including PIPC, CMZ and CTX. Her status became much worse in the afternoon. The second brain CT scan on this day (Fig. 1c) showed severe cerebral edema and enlarged lateral ventricles. A ventriculo-peritoneal shunt was inserted at night under the diagnosis of secondary hydrocephalus. She also received direct intraventricular washing with PIPC without any effect. Her brain CT scan did not show any improvement (Fig. 1d) and she died on 12 July because of multiple organ failure.

\section{DISCUSSION}

L. monocytogenes is widespread in nature, including asymptomatic infection in humans [7]. It is a Gram-positive bacillus that is motile at room temperature. It is the only human pathogen among the seven species in this genus. Although listeriosis usually presents as sepsis of unknown origin and meningitis, the following five categories of infections are known [7]: (i) infection in pregnancy, (ii) granulomatosis infantiseptica, (iii) sepsis of unknown origin, (iv) meningoencephalitis, cerebritis and rhombencephalitis, and (v) focal infections. The most common result of contact with the organism appears to be a transient, asymptomatic carrier state. When illness does occur, it may be mild and only manifest as a brief flu-like syndrome, as seen in some pregnant women, except immunocompromised patients [8].

L. monocytogenes has a predilection for infecting the central nervous system, especially the meninges. In most human cases, the portal of entry is not evident. The patient becomes bacteremic and appears to have sepsis with an unknown source or 
to have meningitis, presumably from bacteremia as in this case. The gastrointestinal tract is considered to be the most likely source, but mucosal lesions are not found [7].

For treatment, ampicillin or penicillin appear to be the best drugs, although other antibiotics have been successfully used in penicillin-allergic patients with listeriosis [7]. As many patients with collagen diseases have penicillin allergy in our experience, we chose CMZ as the initial antibiotic that was also active against $L$. monocytogenes. When the organism was proved to be $L$. monocytogenes, we changed the treatment to PIPC. Treatment failures with penicillin have been reported, and clinical failures do not necessarily indicate antibiotic failure, because in many instances therapy is started late and, particularly in patients with cerebritis, the infection progresses inexorably [7], like this case. In this case, though we treated the patient with antibiotics before the demonstration of bacteremia, the infection progressed because of her immunocompromised status due to MTX therapy [8]. Interferon- $\gamma$ and tumor necrosis factor $\beta$ produced by $\mathrm{T}_{\mathrm{h}} \mathrm{l}$ cells are involved in killing $L$. monocytogenes [9], so $\mathrm{T}_{\mathrm{h}} 1$ cell function may have been mainly affected by MTX in our patient.

Although the mechanisms of the anti-rheumatic effect of MTX is not completely known and many adverse effects, such as hepatic fibrosis, interstitial pneumonia and myelosuppression have been reported [2], MTX is one of the most effective DMARDs, and was recently chosen as a first-line drug of this class in the US and Europe [1].

Tripathy and MacKaness showed that Listeria growth was accelerated in mice given MTX, especially 4 days before infection [6]. They also showed that the immunosuppressive activity of MTX was highest when the drug was administered at $48 \mathrm{~h}$ after infection, indicating that the drug probably acts most effectively on a later stage of the immune response [6]. Because MTX treatment for RA is usually weekly, the infection may progress if $L$. monocytogenes infects a patient between 4 days before and 2 days after taking MTX.

In the literature, four cases of listeriosis associated RA were reported [3-5] including our case (Table 1). All patients had received MTX treatment for more than 15 months. While case 1 [3], who had only received steroid treatment for RA, had no history of sepsis of unknown origin, the other cases $[4,5]$ had a prior history of sepsis. As L. monocytogenes infection most probably occurs via the gastrointestinal tract [7], the treatment with strong antacid medicine is thought to be a trigger. Case 2 [4] received a proton pomp inhibitor (omeprazole) and our case was treated with a histamine- 2 blockade (famotidine $10 \mathrm{mg} /$ day). Although the other patients were improved with penicillin, our case rapidly developed meningoencephalitis and died because initial CMZ therapy was not effective and the infection progressed inexorably.

In the future, MTX treatment for RA will probably increase in Japan because of its strong activity. Potentially fatal listeriosis should be considered in febrile RA patients who are on MTX therapy. 


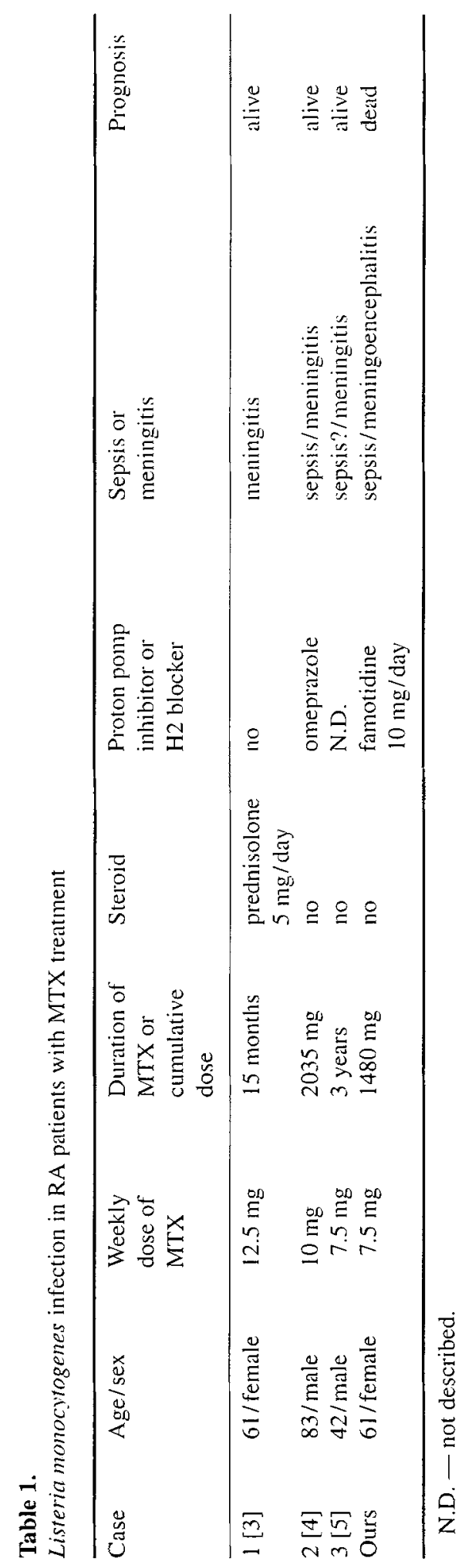




\section{CONCLUSION}

L. monocytogenes infection in an RA patient with MTX therapy was reported. This infection should be considered as a potentially fatal adverse effect of MTX.

\section{REFERENCES}

1. American College of Rheumatology ad hoc committee on clinical guidelines, Guidelines for the management of rheumatoid arthritis, Arthritis Rheum 39, 713-722 (1996).

2. American College of Rheumatology ad hoc committee on clinical guidelines, Guidelines for monitoring drug therapy in rheumatoid arthritis, Arthritis Rheum 39, 723-731 (1996).

3. Gipsen JG, Alarcon GS, Johnson JJ et al., Toxicity to methotrexate in rheumatoid arthritis, J Rheumatol 14, 74-79 (1987).

4. McCambridge MM, Vogelgesang SA, Ockenhouse CF, Listeria monocytogenes infection in a patient treated with methotrexate for rheumatoid arthritis, $J$ Rheumatol 22, 786-787 (1995).

5. Hayem G, Meyer O, Kahn M-F, Listeria monocytogenes infection in a patient treated with methotrexate for rheumatoid arthritis, J Rheumatol 23, 198-199 (1996).

6. Tripathy SP, MacKaness GB, The effect of cytotoxic agents on the primary immune response to Listeria monocytogenes, J Exp Med 130, 1-16 (1969).

7. Armstrong D, Listeria monocytogenes, in: Mandell, Douglas and Bennett's Principles and Practice of Infectious Disease, Mandell GL, Bennett JE, Dolin R (Eds), 4th edn, pp. 1880- 1885. Churchill Livingstone, New York (1995).

8. Skogberg K, Syrjanen J, Jahkola M et al., Clinical presentation and outcome of listeriosis in patients with and without immunosuppressive therapy, Clin Infect Dis 14, 815-821 (1992).

9. Kaufmann SHE, Interleukins, mycobacteria, and listeriae, Diagn Microbiol Infect Dis 13, $429-433$ (1990). 